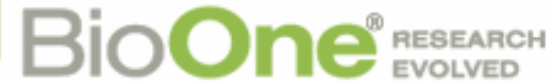

\section{The Disturbance of Resident Populations of Field Voles (Microtus agrestis) by Immigrants}

Author(s): Louise Riotte-Lambert, Alice Rémy \& Harry P. Andreassen

Source: Annales Zoologici Fennici, 49(1/2):103-112.

Published By: Finnish Zoological and Botanical Publishing Board

https://doi.org/10.5735/086.049.0110

URL: http://www.bioone.org/doi/full/10.5735/086.049.0110

BioOne (www.bioone.org) is a nonprofit, online aggregation of core research in the biological, ecological, and environmental sciences. BioOne provides a sustainable online platform for over 170 journals and books published by nonprofit societies, associations, museums, institutions, and presses.

Your use of this PDF, the BioOne Web site, and all posted and associated content indicates your acceptance of BioOne's Terms of Use, available at www.bioone.org/page/ terms of use.

Usage of BioOne content is strictly limited to personal, educational, and non-commercial use. Commercial inquiries or rights and permissions requests should be directed to the individual publisher as copyright holder. 


\title{
The disturbance of resident populations of field voles (Microtus agrestis) by immigrants
}

\author{
Louise Riotte-Lambert ${ }^{1}$, Alice Rémy ${ }^{1,2, \star}$ \& Harry P. Andreassen ${ }^{1}$
}

\author{
1) Faculty of Applied Ecology and Agricultural Sciences, Hedmark University College, Campus \\ Evenstad, Anne Evenstadsvei 80, NO-2480 Koppang, Norway ( ${ }^{*}$ corresponding author's e-mail: \\ remy.alice@neuf.fr, alice.remy@hihm.no) \\ 2) Centre for Ecological and Evolutionary Synthesis, Department of Biology, University of Oslo, \\ P.O. Box 1066, Blindern, NO-0316 Oslo, Norway
}

Received 9 Aug. 2011, final version received 10 Nov. 2011, accepted 10 Nov. 2011

Riotte-Lambert, L., Rémy, A. \& Andreassen, H. P. 2012: The disturbance of resident populations of field voles (Microtus agrestis) by immigrants. - Ann. Zool. Fennici 49: 103-112.

The introduction of immigrants into resident populations may disturb the social organisation of the latter. It is often stated that males compete with males for access to mates, while females compete with females and/or males for limited resources (e.g., nest sites, food). Therefore, the impacts of introductions on residents should depend on the immigrant's sex. To test this hypothesis, we experimentally introduced either male or female immigrants into field vole (Microtus agrestis) populations, and observed the consequences in terms of space use and survival of both residents and immigrants. Our results showed intra-sexual competition: (i) resident females responded to the introduction of females by reducing their home range size and their interactions with neighbours; (ii) immigrant males suffered high mortality, probably due to contests with resident males for access to females. We conclude that the role of social interactions should not be underestimated when releasing unfamiliar individuals into small populations.

\section{Introduction}

Worldwide, progressively more species are becoming endangered and/or are going extinct. To meet this current extinction crisis, one increasingly popular conservation incentive is the reinforcement of wild populations by small groups of individuals, also called supplementation (Fischer \& Lindenmayer 2000). The goal of such conservation actions is that newcomers (i.e. immigrants) will settle as residents and participate in the reproductive effort of the population. Unfortunately, many reinforcement actions carried out in the past failed and the underlying causes remain unknown (Fischer \& Lindenmayer 2000). Recent studies showed that immigrants can have negative impacts on residents' performance through the exploitation of limited resources (e.g., food and mates; Back et al. 2002), contests, and/or infanticides (Lambin \& Krebs 1993, Swenson et al. 1997, Ylönen et al. 1997, Mahady \& Wolff 2002). For example, Andreassen and Gundersen (2006) showed that the introduction of adult males induced a decrease in recruitment and female survival in root voles. Similarly, Lin et al. (2004) found 
that immigration of adult female prairie voles decreased the proportion of resident females and juveniles, changing the sex and age structure of populations. Broadly speaking, when introduced into a population, individuals may disturb the social structure of the resident population through competition, with detrimental effects on population growth (Sutherland \& Norris 2002).

One way to study social interactions is to estimate individual home ranges and overlap between individual territories. Home range is defined as the area used by an individual for its normal activities, like foraging, mating or breeding (Burt 1943). Overlap between individual home ranges is an index of aggressiveness and territorial behaviour (Pitelka 1959, Ostfeld 1985, 1990). Large overlap can indicate non-aggressive behaviour between conspecifics, whereas small or no overlap can indicate territory defence. Studies focusing on the changes in space use of residents following the introduction of immigrants are scarce. Hayes et al. (2004) found that immigrant female prairie voles (Microtus ochrogaster) had larger home ranges than resident females, probably due to their exploratory behaviour and their eviction from resident territories. On the other hand, space use of resident females was not affected by the introduction of females. However, the authors stressed the need to incorporate the effects of the introduction of immigrants on resident males. Indeed, males and females have different strategies when interacting with conspecifics (Brandt 1992, Palanza et al. 1996, Kahlenberg et al. 2008). For resident males, immigrant males represent competitors for mating, while immigrant females represent an additional mating opportunity, so it should be in the resident male's interest to behave aggressively towards males, but not towards females (Back et al. 2002). For resident females, immigrant females represent competitors for limited resources, such as nest sites and food (Kahlenberg et al. 2008, Stockley \& Bro-Jorgensen 2011), and thus should be aggressively repelled. The benefits of male immigration for resident females are less clear: they can represent competitors for food (Back et al. 2002, Schradin 2004), induce spontaneous abortions (Bruce 1960, but see Mahady \& Wolff 2002 for discussion) and be infanticidal (Ylönen et al. 1997), and should also be repelled by resident females. On the other hand, females can accept an additional male and benefit from a multi-male mating strategy (Jennions \& Petrie 2000).

Thus, our study aimed at analysing changes in space use of both male and female residents after the introduction of either an adult male or female immigrant. We also evaluated how immigrants interacted with residents, and observed the consequences in terms of survival for both residents and immigrants. We used the field vole (Microtus agrestis) as a study species, which enabled us to conduct short term experiments while integrating complex behaviours. As stated above, we expected intra-sexual competition between residents and immigrants, especially amongst males.

\section{Material and methods}

\section{Experimental area}

The experiment was carried out during the summer of 2009, in four enclosed plots protected from mammalian predation by an electric device, at Evenstad Research Station, Norway (see Andreassen et al. 1998 for a general description). To prevent voles from escaping, the plots were separated by steel sheets extending $0.4 \mathrm{~m}$ above and $0.6 \mathrm{~m}$ below ground. In addition, to discourage voles from approaching the fence, we mowed the vegetation on a 2-m-wide strip along the fences every second week. Each plot included $400 \mathrm{~m}^{2}$ of vegetation cover (ca. $30 \times$ $13.5 \mathrm{~m}$ for three plots, and $48.5 \times 8.5 \mathrm{~m}$ for one plot; plot identity had no statistical effect on resident home-range sizes: Tukey's test: $p>0.70$ for all pairwise comparisons). Vegetation cover in the plots consisted of a dense meadow, dominated by Poaceae spp. (mainly Alopecurus pratensis, Elymus caninus and Deschampsia spp.), Fabaceae spp. (mainly Trifolium pratense), some Asteraceae spp. (Cirsium arvense and Tanacetum vulgare) and Epilobium angustifolium (Onagraceae spp.). Dense meadow is an optimal habitat for field voles (Pusenius \& Viitala 1993b, Mitchell-Jones et al. 1999), as it provides food and protection from avian predators (Lin \& Batzli 2001). All rodents present in the plots were removed prior to the experiment. 


\section{Study species}

The field vole is a small microtine rodent, distributed across most of northern Europe (Mitchell-Jones et al. 1999). It is characterized by high reproduction rates (Stenseth et al. 1977), a polygynous mating system and a territorial behaviour more commonly displayed by males than by females (see Pusenius \& Viitala 1993b for a review). For the experiment, we used voles caught in the wild (Oppland county, south-eastern Norway). We kept them in wire mesh cages (dimensions: $32 \times 23 \times 20 \mathrm{~cm}$ ) in an outdoor shelter at least two weeks prior to the beginning of the experiment, to ensure that females were not pregnant. During captivity, animals were fed with carrots, apples, sunflower seeds and grass every second day. Before being released in the field, we individually marked voles by toe-clipping (only one toe per individual) to facilitate identification during the experiment.

\section{Experimental treatment}

We repeated the experiment in three consecutive periods between July and August 2009. Each period lasted three weeks, and started with the release of a small population (two adult females and one adult male) into each enclosure. This density of adults (75 adults per hectare) was high to induce competition for territories, as it corresponds to a summer-peak density of breeding individuals for field voles in an optimal habitat (Pusenius \& Viitala 1993b). The chosen sex ratio was similar to that found in other studies focusing on field voles, both in enclosures (Pusenius \& Viitala 1995) and in natural fields (Pusenius \& Viitala 1993a, 1993b). We fitted individuals with radio collars (BD-2C, Holohil Systems Ltd., Canada) in order to estimate their space use patterns. The collars weighted ca $1.5 \mathrm{~g}$, which was less than $10 \%$ of the weight of the voles we used (> $25 \mathrm{~g})$. We, therefore, expected minimal impact of collars on individual behaviours (Andreassen et al. 1993).

We left founder populations undisturbed for one week to allow individuals to become familiar with their new environment and settle down, which seems to be a sufficient time for small rodent species (Nelson 1995, Pusenius \& Viitala 1995, Koskela et al. 1997, Nie \& Liu 2005). Then, we tracked residents by radio-telemetry for five days, between 07:00 and 13:00, and between 16:00 and 20:00, with two consecutive locations for the same individual taken at least 1-h apart. We used a probe antenna attached to a 2-m-long fishing rod (Andreassen et al. 1993, 1998) to locate individuals within a grid of $1 \mathrm{~m}^{2}$ spatial resolution. To minimize disturbing the voles, we always walked along two or three regular pathways within the plots. Radio-tracking enabled us to estimate space use before the introduction of one immigrant. In total, we left these animals for two entire weeks in the field before the introduction of immigrants, therefore we considered these individuals residents. At the end of the second week, we released one immigrant into each plot, either a male or female, and radio-tracked all individuals (residents and immigrants) for five days, as previously described. We confirmed deaths by telemetry, and caught surviving individuals by live-trapping at the end of each period.

In total, we tested 12 populations, six with the introduction of a female and six with the introduction of a male. However, we removed two trials (both including immigrant females) from the data set because we were not able to detect the signal of any of the residents during the third week (even if the animals were alive and caught by live-trapping at the end of the period). Hence, our analyses were performed on 40 individuals (30 residents and 10 immigrants).

\section{Space use estimates}

To estimate home-range size, we used the Minimum Convex Polygon (MCP) method (Mohr 1947). This method was most appropriate for our sampling design and the presence of hard boundaries (i.e. plot fences). Indeed, kernel methods would have estimated home ranges extending outside the enclosed plots (Andreassen et al. 1993). Due to various problems (e.g. collars falling off, premature death of collared individuals, receiver malfunctioning), we did not reach the minimum number of 20 locations per individual that we originally planned. Instead, 
we had numbers of locations ranging from 0 to 17 across all individuals. As the estimation of home-range size increases with the number of observations (before reaching an asymptotical size; see Powell 2000 for a review), we standardized the procedure by taking only 10 measures per individual. Nine out of the 40 individuals had less than 10 observations and were excluded from space use analyses (four resident females, four resident males, and one immigrant male). For the standardized procedure, we randomly selected 10 locations per individual, from which we estimated the home-range size with a 95\% MCP calculation, we repeated the process 1000 times and calculated the average homerange size. Although this methodology provided smaller home-range-size estimates than those observed in previous studies conducted on field voles (Agrell 1995, Nelson 1995), it enabled us to accurately compare home ranges between different types of individuals (Worton 1995). Moreover, these home-range-size estimates were highly correlated with mean square distances, which can be less biased by small numbers of fixes (Pearson's product-moment correlation: $r=$ $\left.0.787, t_{49}=8.93, p<0.001\right)$.

Then, we calculated the home-range overlap between two individuals as follows:

$$
\text { Mean overlap }=\frac{R}{\sqrt{A_{1} A_{2}}},
$$

where $R$ is the area shared by two animals, $A_{1}$ is the area used by individual 1 , and $A_{2}$ is the area used by individual 2 (Minta 1993). As before, we standardized the procedure by randomly selecting 10 positions per individual and by averaging the overlap between 2 individuals over 1000 trials. Due to the composition of founder populations, overlaps between residents' home ranges were calculated either between the two females or between the females and the male.

Finally, we calculated the location of the centre of activity of residents and immigrants (Hayne 1949) during the third week of each period. We hypothesized that the distance between activity centres in resident-immigrant interactions would be greater than the one observed in resident-resident interactions. Moreover, we expected that distance to the nearest vegetation edge would be shorter for immigrants than for residents, which would indicate that immigrants were pushed to the periphery of the available habitat with increasing risks of predation (Hovland et al. 1999).

\section{Statistical analyses}

We performed all analyses with the statistical software R v. 2.8.0 (R Development Core Team 2008). For each test, we used $\alpha=0.05$ for the significance level. For the analyses regarding space use patterns, i.e. home-range size and overlap, we used Linear Mixed Models (LMM), including a random effect identifying the replicates to take into account the non-independence of individuals present in the same plot and during the same period. For clarity's sake we gave a number to each LMM used (see Table 1 for an overview of model specifications). Effects were tested with ANOVA comparing nested models, and interactions were removed from the models when non-significant, to test the effects of single factors. The variable "period" had no significant effect on any of the response variables (all $p>$ 0.307 ) and was removed from the analyses.

For the analyses of home range size, we removed the group of resident males that faced female immigrants, since the sample size of this group was too small to estimate model parameters ( $n=2$; the other two males had no or few locations to measure home range sizes). We log-transformed the variables of home-range sizes to normalize their distribution. As a control, we tested whether home-range sizes were different between the three groups of residents before the introduction of an immigrant (Table 1: LMM 1). Then, we tested whether the space use of residents changed with the introduction of an immigrant, by investigating the effects of the interaction between the factors "time" (i.e. before vs. after) and "resident group" on home range sizes (Table 1: LMM 2), and between the factors "time" and "resident pair", and between the factors "time" and "immigrant sex" on overlaps (Table 1: LMM 3).

We analysed the space use of immigrants to see whether there were differences between sexes, and also between immigrants and residents (Table 1: LMMs 4, 5 and 6). In addition, 
we analysed differences in distance between activity centres in resident-resident interactions and in resident-immigrant interactions (Table 1: LMM 7). We also tested whether distance to the nearest edge was shorter for immigrants than for residents (Table 1: LMM 8). Finally, we compared survival between residents and immigrants, using a binomial Generalized Linear Model.

\section{Results}

\section{Home range size of residents}

Before the reinforcement, there was no significant difference between the groups of residents (LMM 1: Likelihood-Ratio test on the "resident group" term: $\mathrm{LR}=1.31$, df $=2, p=0.520$; Fig. 1). Residents had an average home range size of $35.4 \pm 4.7 \mathrm{~m}^{2}$ (mean $\pm \mathrm{SE}$ ). When we tested whether the introduction of an immigrant had an effect on resident home-range sizes, there was a significant interaction between the variables "time" and "resident group" (LMM 2: LR test on the interaction term "time:resident group": $\mathrm{LR}=13.2$, df $=2, p=0.001)$. Resident

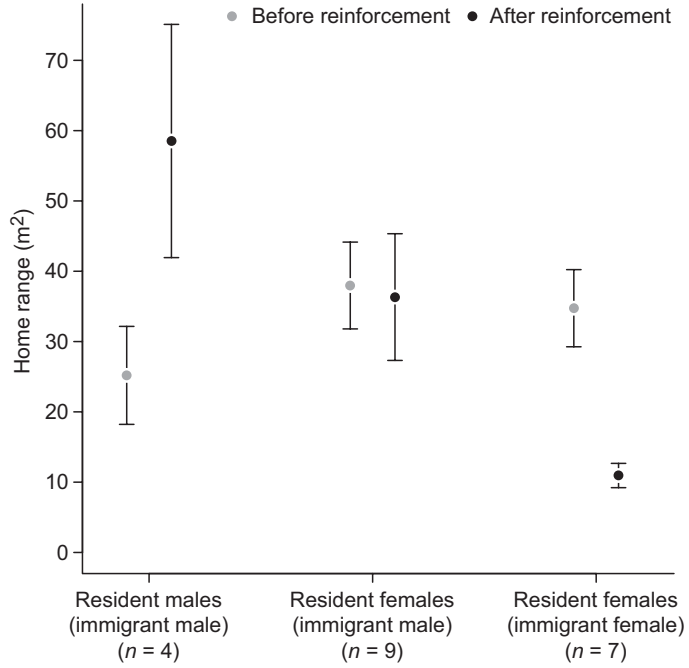

Fig. 1. Average $( \pm \mathrm{SE})$ home range size of residents, before (grey circles) and after (black circles) the introduction of an immigrant.

females reduced their home range with the introduction of an immigrant female, but not with an immigrant male (LMM 2: contrast "resident females (immigrant male)" = $1.07 \pm 0.44, t_{25}$ $=2.44, p=0.022$; Fig. 1), and resident males responded to the introduction of an immigrant

Table 1. Detailed list of the analyses performed to study whether the introduction of an adult immigrant affected the space use of residents, and how immigrants interacted with residents. Variables tested: "resident group" (3 levels: resident males with an immigrant male, resident females with an immigrant male, resident females with an immigrant female); "time" (2 levels: before, after the introduction); "immigrant sex"; "resident pair" (2 levels: male-female residents pair, female-female residents pair); "sex"; "status" (2 levels: resident, immigrant); "status pair" (2 levels: immigrant-resident pair, resident-resident pair).

\begin{tabular}{|c|c|c|}
\hline Study variables & General models & Sample size \\
\hline \multirow[t]{4}{*}{ Home range size of residents (95\% MCP) } & LMM 1: In(home range before the introduction) & \\
\hline & $\sim$ resident group & 20 \\
\hline & LMM 2: In(home range) $\sim$ resident group + time & \\
\hline & + resident group:time & 40 \\
\hline Home range overlap between residents & $\begin{array}{l}\text { LMM 3: Overlap } \sim \text { time }+ \text { immigrant sex }+ \text { resident pair } \\
+ \text { time:immigrant sex + time:resident pair }\end{array}$ & $24^{a}$ \\
\hline \multirow[t]{6}{*}{ Space use of immigrants } & LMM 4: In(home range after the introduction) & \\
\hline & $\sim$ sex + status + sex:status & 31 \\
\hline & LMM 5: Overlap immigrant-resident $\sim$ immigrant sex & $9^{b}$ \\
\hline & LMM 6: Overlap status pair & $21^{b}$ \\
\hline & LMM 7: Distance between individuals status pair & $21^{b}$ \\
\hline & LMM 8: Distance to edges $\sim$ status & 31 \\
\hline
\end{tabular}

\footnotetext{
a When for the same male we had measures of overlap with the two resident females, we used the mean of these overlaps in the analyses.

${ }^{b}$ When for the same immigrant we had measures of overlap/distance with different residents present in the same plot, we used the mean of these overlaps/distances in the analyses.
} 


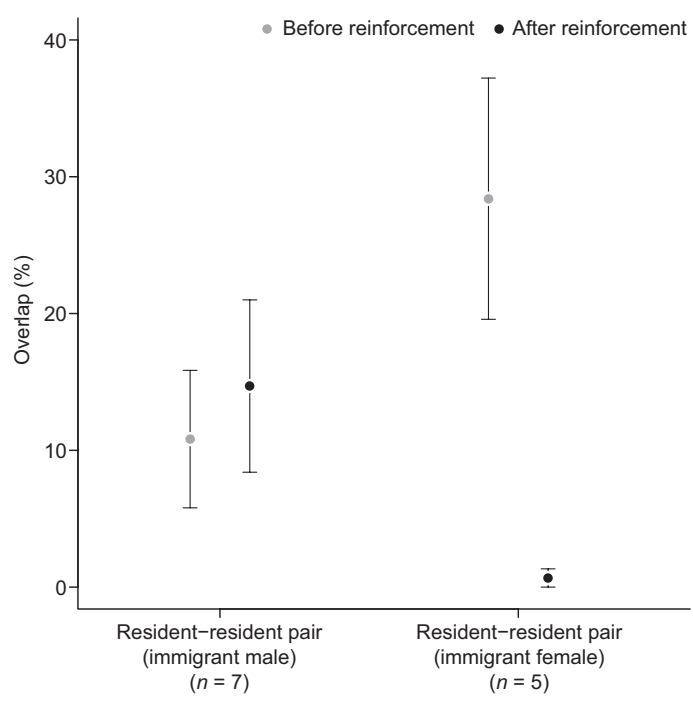

Fig. 2. Average ( \pm SE) overlap between residents, before (grey circles) and after (black circles) the introduction of an immigrant.

male by increasing their home-range size (LMM 2: contrast "resident males (immigrant male)" = $1.93 \pm 0.55, t_{25}=3.52, p=0.002$; Fig. 1 ).

\section{Social interactions between residents, estimated by home range overlaps}

Residents' response to the introduction of an immigrant did not significantly differ between male-female pairs and female-female pairs (LMM 3: LR test on the interaction term "time:resident pair": $\mathrm{LR}=1.23$, df $=1, p=$ 0.267). However, resident populations responded differently to the introduction of a male or a female (LMM 3: LR test on the interaction term "time:immigrant sex": $\mathrm{LR}=10.8, \mathrm{df}=1, p=$ 0.001). When introducing a female, residents responded by decreasing their territory overlap with other residents, whereas when a male was introduced, residents did not significantly change their territory overlap (Fig. 2).

\section{Integration of immigrants into the populations}

Immigrants had an average home-range size of $35.5 \pm 11.6 \mathrm{~m}^{2}$ (mean $\left.\pm \mathrm{SE}\right)$. Home-range sizes of individuals were not significantly affected by the interaction between the sex and the status of individuals (LMM 4: LR test on the interaction term "sex:status": $\mathrm{LR}=0.10, \mathrm{df}=1, p=0.749$ ), nor by the status itself (LMM 4: LR test on the "status" term: $\mathrm{LR}=1.67, \mathrm{df}=1, p=0.196)$. However, home-range sizes after the introduction of the immigrant were affected by the sex of individuals, with both resident and immigrant males having larger home ranges than females (LMM 4: LR test on the "sex" term: $\mathrm{LR}=5.90$, $\mathrm{df}=1, p=0.015$ ).

When testing for territory overlap, immigrant males did not share more space with residents than did immigrant females (LMM 5: LR test on the "immigrant sex" term: $\mathrm{LR}=1.40, \mathrm{df}=1, p=$ 0.236 ; mean $\pm \mathrm{SE}=12.2 \% \pm 3.9 \%$ ). Moreover, overlaps involving an immigrant and a resident were similar to those involving two residents (LMM 6: LR test on the "status pair" term: LR = 0.36 , $\mathrm{df}=1, p=0.549$ ). In addition, the distance between activity centres in resident-immigrant interactions was not significantly different than the one in resident-resident interactions (LMM 7: LR test on the "status pair" term: $\mathrm{LR}=0.17$, $\mathrm{df}=1, p=0.682$; mean $\pm \mathrm{SE}=9.7 \pm 1.2 \mathrm{~m})$. The activity centre of immigrants was also not significantly closer to edges than the activity centre of residents (LMM 8: LR test on the "status" term: $\mathrm{LR}=0.41, \mathrm{df}=1, p=0.519$; mean $\pm \mathrm{SE}=$ $5.6 \pm 0.4 \mathrm{~m})$.

Immigrants had a significantly lower survival than residents: 5 out of 10 immigrants died during the experiment, whereas only 3 out of 30 residents died (GLM with binomial family: contrast Residents $=2.2 \pm 0.9, Z=2.50, p=$ $0.012)$. Among the five dead immigrants, four were males.

\section{Discussion}

Our study aimed at determining whether the introduction of an adult immigrant male or female field vole affected resident populations. Despite our small sample sizes, we were able to detect some significant responses to the treatment. We showed that the introduction of adult females had a great impact on residents' space use by inducing a decrease in home-range sizes 
of resident females and in home range overlaps between residents. This latter result may be an indirect effect of the decrease in females' home range sizes as all home range overlap analyses among residents involved a female. Regarding immigrants, their home-range sizes were similar to those of residents and they did not seem to be excluded from the habitat patches (when considering the distance between the different individuals and distance to the nearest edge). However, immigrant males suffered from high mortality following the first week after release. These results may emphasize the relative importance of intra-sexual competition between residents and immigrants during reinforcement actions.

The response of resident females to the introduction of a female we showed here was different than the one observed in prairie voles (Hayes et al. 2004), where females successfully defended their territories against an introduced female without changing their home-range size. In contrast, our results suggest that resident females strengthened their territorial defence by reducing their home range and apparently their social interactions. These contrasting results may be related to the different mating systems of these species. In prairie voles, breeding pairs share a home range that they defend against conspecifics, as other monogamous mammals (Kleiman 1977). Thus, no notable change in territoriality might be observed for resident female prairie voles since the cost of territory defence is relatively low compared to female field voles that defend their territory alone. On the other hand, one can argue that these changes in space use patterns we observed were due to a time effect, as female voles can shrink their home range during pregnancy (Koskela et al. 1997). However, we did not observe the same response when introducing a male, and rates of pregnancy did not seem to differ between the different groups of resident females (available data for only one period: 3 out of 4 pregnant females in the "immigrant male" treatment and 2 out of 4 pregnant females in the "immigrant female" treatment). So, we believe that the females' response showed here was the result of intrasexual competition.

Interestingly, previous studies found low levels or absence of aggressiveness between female field voles (Erlinge et al. 1990a, Agrell 1995). The latter study even showed that when introducing an unfamiliar female (present in a small cage) into the home range of a resident overwintered female, the latter avoided the cage. Therefore, the potential strengthening of female territorial defence in our experiment may not result from direct aggressive interactions, but rather from female avoidance of other females. The relatively low mortality of immigrant females (one out of six females released) supports this idea.

Food was not the main source of competition for resident females, because if it was, they would have responded similarly to the introduction of a male or a female immigrant (resource defence hypothesis; Back et al. 2002). The chosen density of adults might have been high enough to induce competition for breeding territories, but too low to induce competition for food, as population densities can reach up to 300 individuals per hectare during a breeding season (including both adults and recruits; Myllymäki 1977, Lambin et al. 2000, Bierman et al. 2006). Thus, nest-site defence against same-sex conspecifics was likely the driving force leading to females' territoriality in the context of our experiment, which is an adaptive strategy as it determines the future reproductive success of females (Wolff 1993). The apparent nonresponse of resident females to immigrant males might indicate that the latter were not perceived as a threat to the reproductive success of resident females, through infanticide of pups, as these females were only pregnant or not reproductive when the immigrants were introduced. However, we cannot exclude the possibility that resident females would attack immigrant males during the period of lactation. Indeed, differences in aggressiveness according to the reproductive stages and the sex of opponents were found in house mice (Mus musculus domesticus), where females attack more often female than male intruders when they are either not reproductive or pregnant, but they attack males and females similarly when lactating (Palanza et al. 1996).

Resident males had similar home range sizes than resident females before the introduction of an immigrant. We should be careful with the interpretation of these results because our 
sample sizes were small. However, if this trend is confirmed it would contradict previous studies conducted on field voles showing that males have larger home ranges than females during the reproductive season (Erlinge et al. 1990b, Pusenius \& Viitala 1993b). It might be that males restricted their home range to the minimum area including both mates, before we introduced an immigrant. Then, they increased their homerange size likely to patrol their territory and evict the immigrant male. Similarly, when the mating opportunities per male were reduced (low operational sex ratio), males had larger home ranges (see Nelson 1995). To avoid such a trend, future studies would need to start with larger population sizes (implying also larger enclosures), with the release of at least two resident males, which would already express their territorial behaviour before the introduction of immigrants. Considering the high mortality rate of immigrant males, our results suggest that competition between resident and immigrant males was strong, as we predicted under the mate defence hypothesis (Back et al. 2002). We dissected one of the dead male immigrants and found several subcutaneous wounds (biting marks), suggesting that the immigrant died as a result of fights with conspecifics. Because of the early decomposition state of other dead individuals, we were unable to determine the cause of their death.

When considering immigrants' space use only (without regards to mortality rates), no pattern indicated that immigrants were actively excluded from the populations. Indeed, immigrants had similar home ranges, overlaps and distances between centres of activity with conspecifics, to that of residents. In addition, immigrants did not seem to be pushed towards the edges, which might represent a higher risk of predation (Hovland et al. 1999; but see Stamps et al. 1987 for benefits of settling close to hard edges). Hayes et al. (2004) showed that immigrant females moved greater distances and had larger home ranges than resident females. These contrasting results can be explained by the relatively small size of our plots that can constrain individuals' movements (Fauske et al. 1997); immigrants might have been limited in their exploratory behaviour and restricted to vacant areas. However, by comparing the small home-range sizes of individuals to the size of the plots ( $35 \mathrm{vs} .400 \mathrm{~m}^{2}$ ), and by comparing these home range sizes to those found in other populations of field voles, which range from 218 to $379 \mathrm{~m}^{2}$ for males (Nelson 1995) and from 90 to $158 \mathrm{~m}^{2}$ for females for similar time periods (Agrell 1995), we stress the need to increase the number of spatial locations to determine whether our small estimates of individuals' space use were more an artefact of the small number of locations per individual than a result of the small size of the plots.

To conclude, it seems that the introduction of an adult immigrant can either fail or disturb the social organisation of residents depending on the immigrant's sex. Knowing the behaviour of individuals and the social system of species seems therefore crucial for the success of reinforcement projects (Lonsdorf 2007). As an example, reintroductions of male chimpanzees into wild populations often failed due to the high aggressiveness of resident males towards them (Tutin et al. 2001), whereas releasing young females is more successful, as they are less likely to be attacked by residents or to disturb local populations (Goossens et al. 2005). We cannot exclude the possibility that the introduction of young, immature field voles would have induced different responses from residents. Moreover, our results are only valid for the reproductive season, since during the non-breeding season competition for nest sites and mates does not occur and territorial behaviour weakens in microtines (Erlinge et al. 1990b, Ylönen \& Viitala 1991, Hoset et al. 2008). In addition, our study suffers from weaknesses, such as low sample sizes, small spatial and temporal scales, and the absence of the males' response to the introduction of an adult female. We should therefore be cautious about the generalization of these results and further research needs to be done to gain insights into the impacts of introducing unfamiliar individuals on space use patterns and social organisation of resident populations.

\section{Acknowledgments}

We thank J. Damerau, M. Martin, B. Stenou, P. Atanga and A.-S. Bonnet-Lebrun for field assistance. We also thank F. M. van Beest, as well as two anonymous referees for their 
constructive comments on the manuscript. This project was funded by a grant from the Norwegian Research Council (NFR project 182612). The experimentation at Evenstad Research Station was done in accordance with the Norwegian "Animal Welfare Act" (\#73) of 20 Dec. 1974, and the Norwegian "Regulation on Animal Experimentation" of 15 Jan. 1996

\section{References}

Agrell, J. 1995: A shift in female social organization independent of relatedness: an experimental study on the field vole (Microtus agrestis). - Behavioral Ecology 6: 182-191.

Andreassen, H. P. \& Gundersen, G. 2006: Male turnover reduces population growth: an enclosure experiment on voles. - Ecology 87: 88-94.

Andreassen, H. P., Hertzberg, K. \& Ims, R. A. 1998: Spaceuse responses to habitat fragmentation and connectivity in the root vole Microtus oeconomus. - Ecology 79: $1223-1235$.

Andreassen, H. P., Ims, R. A., Stenseth, N. C. \& Yoccoz, N. G. 1993: Investigating space use by means of radiotelemetry and other methods: a methodological guide. - In: Stenseth, N. C. \& Ims, R. A. (eds.), The biology of lemmings: 589-618. Academic Press, London.

Back, S. R., Beeler, L. A., Schaefer, R. L. \& Solomon, N. G. 2002: Testing functional hypotheses for the behavior of resident pine voles, Microtus pinetorum, toward nonresidents. - Ethology 108: 1023-1039.

Bierman, S. M., Fairbairn, J. P., Petty, S. J., Elston, D. A., Tidhar, D. \& Lambin, X. 2006: Changes over time in the spatiotemporal dynamics of cyclic populations of field voles (Microtus agrestis L.). - American Naturalist 167: $583-590$

Brandt, C. A. 1992: Social factors in immigration and emigration. - In: Stenseth, N. C. \& Lidicker, W. Z. J. (eds.), Animal dispersal: small mammals as a model: 96-141. Chapman and Hall, London.

Bruce, H. M. 1960: A block to pregnancy in the mouse caused by proximity of strange males. - Journal of Reproduction and Fertility 1: 96-103.

Burt, W. H. 1943: Territoriality and home range concepts as applied to mammals. - Journal of Mammalogy 24: 346-352.

Erlinge, S., Agrell, J., Nelson, J. \& Sandell, M. 1990a: Social organization and population dynamics in a Microtus agrestis population. - In: Tamarin, R. H., Ostfeld, R. S., Pugh, S. R. \& Bujalska, G. (eds.), Social systems and population cycles in voles: 35-48. Birkhauser Verlag, Basel.

Erlinge, S., Hoogenboom, I., Agrell, J., Nelson, J. \& Sandell, M. 1990b: Density-related home-range size and overlap in adult field voles (Microtus agrestis) in southern Sweden. - Journal of Mammalogy 71: 597-603.

Fauske, J., Andreassen, H. P. \& Ims, R. A. 1997: Spatial organization in a small population of the root vole Microtus oeconomus in a linear habitat. - Acta Therio- logica 42: 79-90.

Fischer, J. \& Lindenmayer, D. B. 2000: An assessment of the published results of animal relocations. - Biological Conservation 96: 1-11.

Goossens, B., Setchell, J. M., Tchidongo, E., Dilambaka, E., Vidal, C., Ancrenaz, A. \& Jamart, A. 2005: Survival, interactions with conspecifics and reproduction in 37 chimpanzees released into the wild. - Biological Conservation 123: 461-475.

Hayes, L. D., Lin, Y. K. \& Solomon, N. G. 2004: The effect of female prairie vole (Microtus ochrogaster) immigrants on space use of conspecific female residents. American Midland Naturalist 151: 88-92.

Hayne, D. W. 1949: Calculation of size of home range Journal of Mammalogy 30: 1-18.

Hoset, K. S., Le Galliard, J. F., Gundersen, G. \& Steen, H. 2008: Home range size and overlap in female root voles: effects of season and density. - Behavioral Ecology 19: 139-145.

Hovland, N., Andreassen, H. P. \& Ims, R. A. 1999: Foraging behaviour of the root vole Microtus oeconomus in fragmented habitats. - Oecologia 121: 236-244.

Jennions, M. D. \& Petrie, M. 2000: Why do females mate multiply? A review of the genetic benefits. - Biological Reviews 75: 21-64.

Kahlenberg, S. M., Thompson, M. E., Muller, M. N. \& Wrangham, R. W. 2008: Immigration costs for female chimpanzees and male protection as an immigrant counterstrategy to intrasexual aggression. - Animal Behaviour 76: 1497-1509.

Kleiman, D. G. 1977: Monogamy in mammals. - Quarterly Review of Biology 52: 39-69.

Koskela, E., Mappes, T. \& Ylonen, H. 1997: Territorial behaviour and reproductive success of bank vole Clethrionomys glareolus females. - Journal of Animal Ecology 66: 341-349.

Lambin, X. \& Krebs, C. J. 1993: Influence of female relatedness on the demography of Townsend's vole populations in spring. - Journal of Animal Ecology 62: 536-550.

Lambin, X., Petty, S. J. \& MacKinnon, J. L. 2000: Cyclic dynamics in field vole populations and generalist predation. - Journal of Animal Ecology 69: 106-118.

Lin, Y. T. K. \& Batzli, G. O. 2001: The influence of habitat quality on dispersal, demography, and population dynamics of voles. - Ecological Monographs 71 : 245-275.

Lin, Y. K., Hayes, L. D. \& Solomon, N. G. 2004: Effects of female immigrants on demography and social organization of prairie vole (Microtus ochrogaster) populations. - Journal of Mammalogy 85: 781-787.

Lonsdorf, E. V. 2007: The role of behavioral research in the conservation of chimpanzees and gorillas. - Journal of Applied Animal Welfare Science 10: 71-78.

Mahady, S. J. \& Wolff, J. O. 2002: A field test of the Bruce effect in the monogamous prairie vole (Microtus ochrogaster). - Behavioral Ecology and Sociobiology 52: 31-37.

Minta, S. C. 1993: Sexual differences in spatiotemporal interaction among badgers. - Oecologia 96: 402-409.

Mitchell-Jones, A. J., Amori, G., Bogdanowicz, W., Kryštu- 
fek, B., Reijnders, P. J. H., Spitzenberger, F., Stubbe, M., Thissen, J. B. M., Vohralík, V. \& Zima, J. 1999: The atlas of European mammals. - Academic Press, London.

Mohr, C. O. 1947: Table of equivalent populations of North American small mammals. - American Midland Naturalist 37: 223-249.

Myllymäki, A. 1977: Demographic mechanisms in fluctuating populations of field vole Microtus agrestis. - Oikos 29: 468-493.

Nelson, J. 1995: Determinants of male spacing behavior in microtines: an experimental manipulation of female spatial distribution and density. - Behavioral Ecology and Sociobiology 37: 217-223.

Nie, H. \& Liu, J. 2005: Regulation of root vole population dynamics by food supply and predation: a two-factor experiment. - Oikos 109: 387-395.

Ostfeld, R. S. 1985: Limiting resources and territoriality in microtine rodents. - American Naturalist 126: 1-15.

Ostfeld, R. S. 1990: The ecology of territoriality in small mammals. - Trends in Ecology \& Evolution 5: 411-415.

Palanza, P., Re, L., Mainardi, D., Brain, P. F. \& Parmigiani, S. 1996: Male and female competitive strategies of wild house mice pairs (Mus musculus domesticus) confronted with intruders of different sex and age in artificial territories. - Behaviour 133: 863-882.

Pitelka, F. A. 1959: Numbers, breeding schedule, and territoriality in pectoral sandpipers of Northern Alaska. - The Condor 61: 233-264.

Powell, R. A. 2000: Animal home ranges and territories and home range estimators. - In: Boitani, L. \& Fuller, T. K. (eds.), Research techniques in animal ecology: controversies and consequences: 442. Columbia University Press, New York.

Pusenius, J. \& Viitala, J. 1993a: Demography and regulation of breeding density in the field vole, Microtus agrestis. - Annales Zoologici Fennici 30: 133-142.

Pusenius, J. \& Viitala, J. 1993b: Varying spacing behavior of breeding field voles, Microtus agrestis. - Annales Zoologici Fennici 30: 143-152.

Pusenius, J. \& Viitala, J. 1995: Familiarity of breeding field vole (Microtus agrestis) females does not affect their space use and demography of the population. - Annales
Zoologici Fennici 32: 217-223.

R Development Core Team 2008: $R$ : A language and environment for statistical computing. - $\mathrm{R}$ Foundation for Statistical Computing, Vienna, Austria, available at http://www.R-project.org.

Schradin, C. 2004: Territorial defense in a group-living solitary forager: who, where, against whom? - Behavioral Ecology and Sociobiology 55: 439-446.

Stamps, J. A., Buechner, M. \& Krishnan, V. V. 1987: The effects of habitat geometry on territorial defense costs: intruder pressure in bounded habitats. - American Zoologist 27: 307-325.

Stenseth, N. C., Hansson, L., Myllymäki, A., Andersson, M. \& Katila, J. 1977: General models for population dynamics of field vole Microtus agrestis in central Scandinavia. - Oikos 29: 616-642.

Stockley, P. \& Bro-Jorgensen, J. 2011: Female competition and its evolutionary consequences in mammals. - Biological Reviews 86: 341-366.

Sutherland, W. J. \& Norris, K. 2002: Behavioural models of population growth rates: implications for conservation and prediction. - Philosophical Transactions of the Royal Society of London B 357: 1273-1284.

Swenson, J. E., Sandegren, F., Söderberg, A., Bjärvall, A., Franzén, R. \& Wabakken, P. 1997: Infanticide caused by hunting of male bears. - Nature 386: 450-451.

Tutin, C. E. G., Ancrenaz, M., Paredes, J., Vacher-Vallas, M., Vidal, C., Goossens, B., Bruford, M. W. \& Jamart, A. 2001: Conservation biology framework for the release of wild-born orphaned chimpanzees into the Conkouati Reserve, Congo. - Conservation Biology 15: 1247-1257.

Wolff, J. O. 1993: Why are female small mammals territorial? - Oikos 68: 364-370.

Worton, B. J. 1995: A convex hull-based estimator of homerange size. - Biometrics 51: 1206-1215.

Ylönen, H. \& Viitala, J. 1991: Social overwintering and food distribution in the bank vole Clethrionomys glareolus. - Holarctic Ecology 14: 131-137.

Ylönen, H., Koskela, E. \& Mappes, T. 1997: Infanticide in the bank vole (Clethrionomys glareolus): occurrence and the effect of familiarity on female infanticide. Annales Zoologici Fennici 34: 259-266. 